\title{
Prevalence and Clinical Correlates of Spontaneous Echo Contrast in Patients on Oral Anticoagulation Undergoing Catheter Ablation for Atrial Fibrillation
}

\author{
Christian Grebmer ${ }^{1 *}$, Carsten Lennerz ${ }^{1,2}$, Amir Brkic ${ }^{1}$, Patrick Blazek ${ }^{1}$, Severin \\ Weigand $^{1,2}$, Verena Semmler ${ }^{1}$, Marc Kottmaier ${ }^{1}$, Felix Bourier ${ }^{1}$, Lena Friedrich ${ }^{1}$, \\ Elena Risse ${ }^{1}$, Stephanie Brooks ${ }^{1}$, Marie Kornmayer ${ }^{1}$, Marta Telishevska $^{1}$, Tilko \\ Reents $^{1}$, Christof Kolb ${ }^{1,2}$, Gabriele Hessling ${ }^{1,2}$ and Isabel Deisenhofer ${ }^{1,2}$
}

${ }^{1}$ Deutsches Herzzentrum München, Klinik für Herz- und Kreislauferkrankungen, Abteilung Elektrophysiologie, Technische Universität München, Munich, Germany

${ }^{2}$ DZHK (German Centre for Cardiovascular Research), Partner site Munich Heart Alliance, Munich, Germany

*Corresponding author: Dr. med. univ. Christian Grebmer, Deutsches Herzzentrum München, Lazarettstr. 36, 80636 München, Germany, Tel: 0049-89-1218-2020, Fax: 0049-89-1218-4593

\begin{abstract}
Background: Spontaneous echo contrast (SEC) in the left atrial appendage (LAA) is associated with an increased risk of cerebral embolism in patients with atrial fibrillation (AF). Novel oral anticoagulants (NOACs) are increasingly prescribed as first-line therapy and have shown a comparable benefit-risk ratio compared to vitamin $\mathrm{K}$ antagonists (VKAs). The aim of this study was to investigate whether NOACs decrease the incidence of SEC compared to VKA.

Methods: We retrospectively analysed 542 patients who underwent transoesophageal echocardiography (TEE) prior to AF ablation at our institution. SEC was characterised by dynamic, smoke-like echoes within the LA cavity or LAA on TEE.

Results: SEC was detected in 58 patients (10.7\%) and occurred significantly more often in patients on VKA $(n=39$; $13.6 \%$ ) compared to patients on NOACs ( $n=19,7.5 \%$; $p=$ $0.02)$. Decreased left ventricular function $(p<0.001)$, arterial hypertension $(p<0.001)$, LA enlargement $(p<0.001)$ and AF during TEE $(p<0.001)$ were significantly more often observed in patients showing SEC. Transient ischemic attack or stroke did not occur in any patient during AF ablation.

Conclusion: The incidence of SEC on TEE in patients prior to AF ablation was significantly lower in patients treated with NOACs as compared to patients treated with VKA. Patients with multiple risk factors showed a higher SEC incidence. The results support the recommendation of NOACs as firstline oral anticoagulation in non-valvular AF.
\end{abstract}

\section{Keywords}

Spontaneous echo contrast, Atrial fibrillation, Transoesophageal echocardiography

\section{Background}

A recently published article indicates no correlation between periprocedural thromboembolic events and spontaneous echo contrast (SEC) in patients undergoing catheter ablation of atrial fibrillation (AF). However, during long-term follow-up, patients with preprocedurally detected SEC showed significantly more strokes/ transient ischemic attacks (TIAs) [1]. Additionally, SEC in the left atrial appendage (LAA) is associated with an increased risk of cerebral embolism in patients with $A F$, even if sufficiently anticoagulated [2].

During past years, new agents other than the established vitamin $\mathrm{K}$ antagonists (VKA) entered the arena of oral anticoagulation-the so-called novel oral anticoagulants (NOACs). Previous reports have stated the clinical effectiveness of NOACs in patients with non-valvular AF [3-6]. Due to good compliance and effectiveness, the use of NOACs is increasing, but clinical experience is still limited [7]. In the present study, we investigated whether patients under NOACs exhibit a lower incidence of

Citation: Grebmer C, Lennerz C, Brkic A, Blazek P, Weigand S, et al. (2019) Prevalence and Clinical Correlates of Spontaneous Echo Contrast in Patients on Oral Anticoagulation Undergoing Catheter Ablation for Atrial Fibrillation. Int J Clin Cardiol 6:151. doi.org/10.23937/2378-2951/1410151

Accepted: June 17, 2019; Published: June 19, 2019

Copyright: (C) 2019 Grebmer C, et al. This is an open-access article distributed under the terms of the Creative Commons Attribution License, which permits unrestricted use, distribution, and reproduction in any medium, provided the original author and source are credited. 


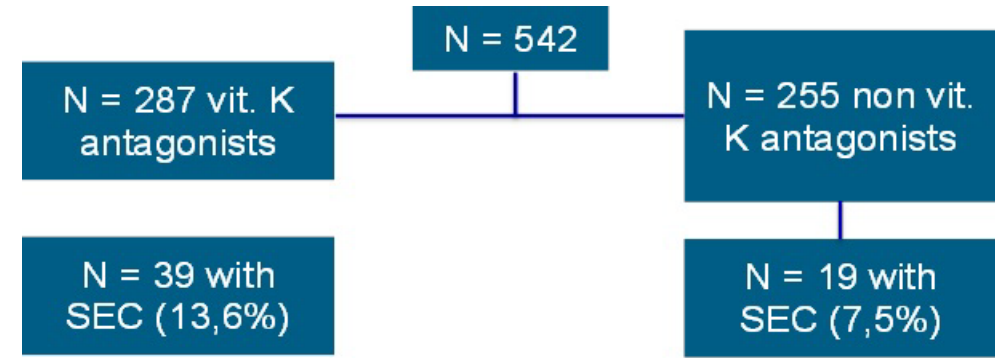

Figure 1: Incidence of SEC (spontaneous echo contrast) in patients on vitamin K-antagonists and NOACs (novel oral anticoagulants).

Table 1: Differences in baseline characteristics in patients with or without SEC.

\begin{tabular}{|l|l|l|l|}
\hline & No SEC & SEC & p-value \\
\hline Gender & $63.4 \%$ (male) & $53.4 \%$ (male) & 0.131 \\
\hline Type of atrial fibrillation & $40.4 \%$ (pers.) & $87.9 \%$ (pers.) & $<0.001^{*}$ \\
\hline Rhythm at TEE & $40 \%$ (afib) & $84.5 \%$ (afib) & $<0.001^{* *}$ \\
\hline NOAC & $48.70 \%$ & $32.80 \%$ & $00.02^{*}$ \\
\hline Hypertension & $71.30 \%$ & $91.50 \%$ & $<0.001^{* *}$ \\
\hline
\end{tabular}

SEC compared to patients under VKA.

\section{Methods}

\section{Study population}

Our retrospective analysis included all patients who underwent catheter ablation for paroxysmal or persistent AF at our centre from January 2013 to December 2014 and who received transoesophageal echocardiography (TEE) to exclude intra-atrial thrombus. All patients were examined for SEC. SEC was characterised by dynamic, smoke-like echoes within the LA cavity or LAA during TEE [8]. Patients taking VKA who were not in the therapeutic window (INR between 2.0 and 3.0) were excluded from the analysis.

\section{Transesophageal echocardiography}

Two-dimensional (2D) and three-dimensional (3D) TEE were performed with a commercially available ultrasound system (Phillips iE33; Philips Medical Systems, Andover, MA, USA) using a matrix-array 3D TEE probe (X7-2t; Philips Medical Systems). All TEEs were performed within $24 \mathrm{~h}$ prior to the scheduled procedure. SEC was defined as dynamic, smoke-like echoes with swirling motion using optimal gain setting during the cardiac cycle. Thrombus, on the other hand, was defined as a circumscribed and uniformly echo-dense intracavitary mass distinct from the underlying LA or LAA endocardium [8].

\section{Statistical analysis}

Data analysis was performed using the software package SPSS for Windows versions 23.0 (IBM Corp., Armonk, NY, USA). Two sample t-tests were performed in the case of normal distribution of the variables, and Mann-Whitney-Wilcox tests were performed in the case of the remaining distributions. A linear regression analysis was conducted to determine the relationship between the SEC and selected variables (risk factors). For categorical outcomes including relative frequencies, group comparisons were performed using chi-squared tests. For quantitative measures, means and standard deviations for symmetrically distributed data or medians and ranges (minimum to maximum) for skewed data were shown.

\section{Results}

A total of 542 patients were included in the study (VKA, $n=287$; NOAC, $n=255$ ). Within the NOAC group, $18.4 \%$ of patients $(n=47)$ received dabigatran, $22 \%$ $(n=56)$ apixaban, and $59.6 \%(n=152)$ rivaroxaban. $A$ reduced dose of the NOACs was administered in $11 \%$ (n $=28$ ) of patients. No intra-atrial thrombus was found in this population.

SEC was significantly more often present in patients on VKA $(13.6 \%)$ as compared to patients on NOACs $(7.5 \%)(p=0.02$; Table 1; Figure 1).

Decreased left ventricular function $(p<0.001)$, arterial hypertension $(p<0.001)$, LA enlargement $(p<$ $0.001)$ and AF during TEE $(p<0.001)$ were significantly more often found in patients exhibiting SEC (Table 1 and Table 2; pages 12 and 13).

The number of previous ablation procedures was not associated with a higher SEC incidence $(p=0.53)$, but we found a significantly higher SEC incidence in patients with persistent $\mathrm{AF}$ versus patients with paroxysmal $\mathrm{AF}$ $(p<0.001$; Figure 2 and Figure 3; page 15).

Logistic regression (Table 3, page 13) demonstrated a clinically relevant increased risk for SEC by age (5.4\%/ year), total duration of persistent AF (1.7\%/month), number of previous cardioversions (22.3\%/each), LA diameter $(6.5 \% / \mathrm{mm})$ and CHADS2 score (6.5\%/point). 
Table 2: Differences in baseline characteristics in patients with and without SEC.

\begin{tabular}{|l|l|l|l|l|l|}
\hline & No SEC & \multicolumn{2}{l|}{ SEC } & p-value \\
\hline Age & mean & SD & mean & SD & $<0.001^{* *}$ \\
\hline Number of previous AF Ablations & 63.89 & 10.6 & 68.48 & 7.69 & 0.53 \\
\hline LV-EF (\%) & 1.77 & 0.77 & 1.71 & 0.75 & $<0.001^{* *}$ \\
\hline LA-Diameter (mm) & 54.52 & 7.58 & 50.6 & 9.63 & $<0.001^{* *}$ \\
\hline CHADS $_{2}$ & 38.66 & 11.78 & 45.88 & 9.52 & $0.01^{*}$ \\
\hline CHA $_{2}$ DS $_{2}$-VASc & 1.29 & 1.1 & 1.67 & 1.01 & $<0.001^{* *}$ \\
\hline
\end{tabular}

Note: ${ }^{*}=$ Significant and ${ }^{* *}=$ Highly significant.

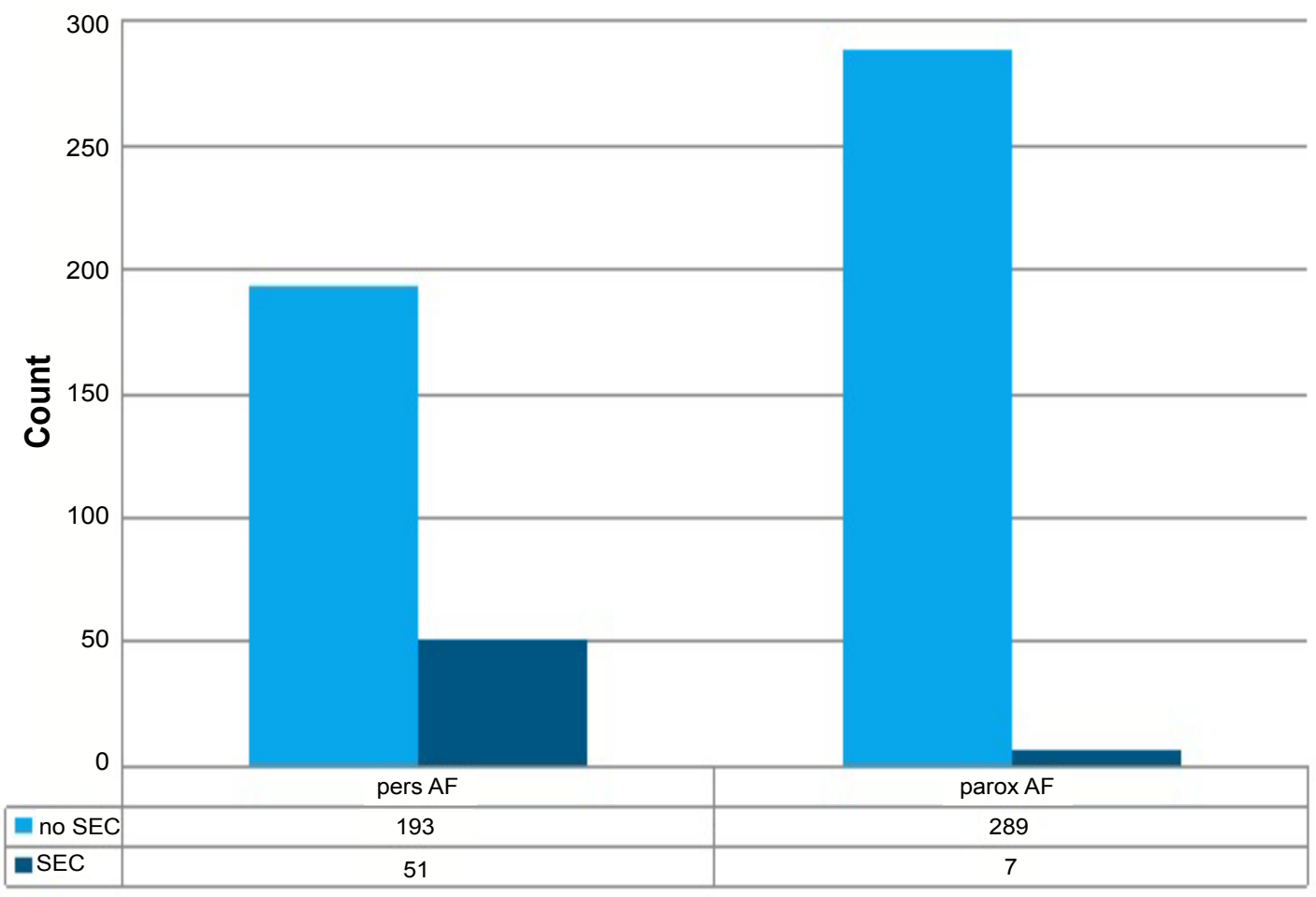

Figure 2: Count of patients with paroxysmal versus persistent AF in context of prevalence of SEC.

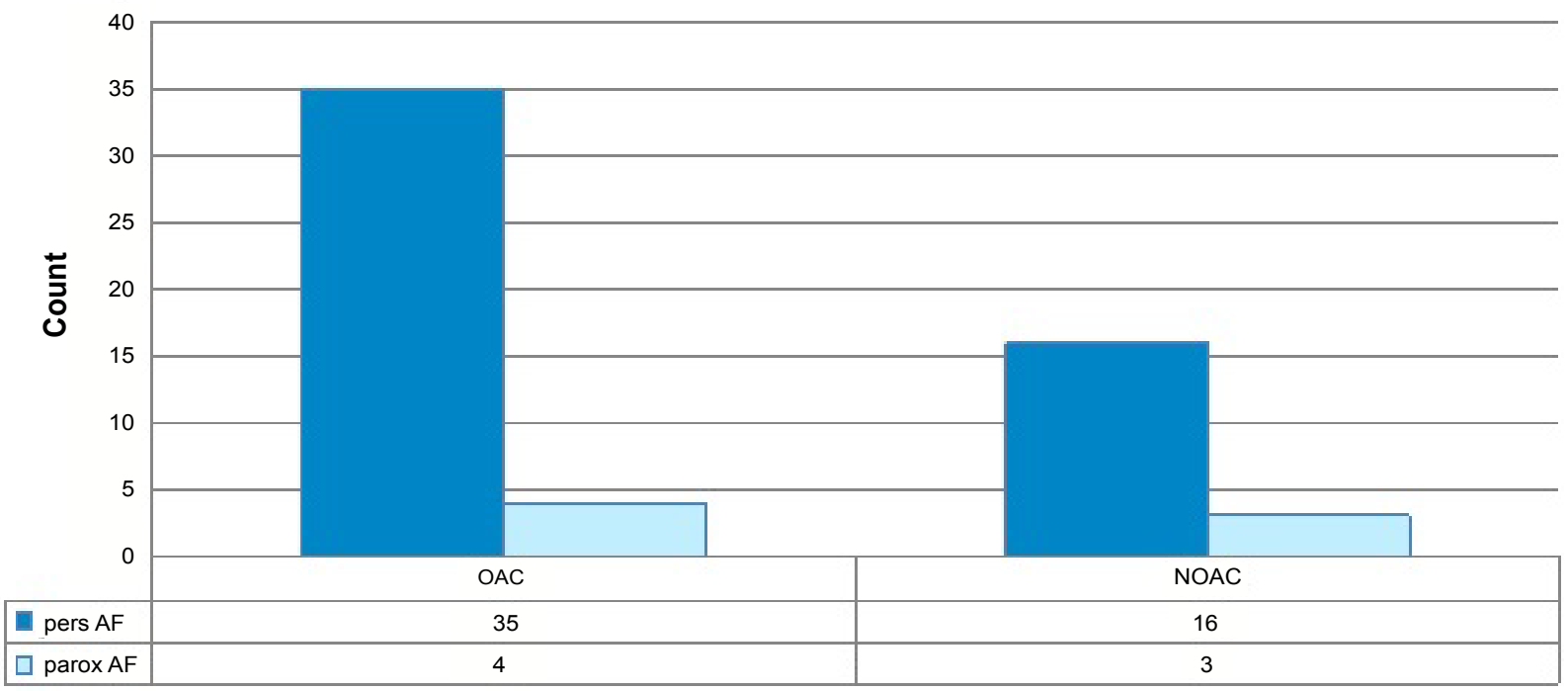

Figure 3: NOAC versus vitamin $\mathrm{K}$ antagonists $(\mathrm{OAC})$ in patients with $\mathrm{SEC}$ in context of prevalence of pers. and paroxysmal AF. 
Table 3: Logistic regression (IV: age, total AF-duration in months, persistent AF duration in months, number of previous cardioversions, LV-function, LA-diameter, $\mathrm{CHADS}_{2}$ score; dependent variable.

\begin{tabular}{|l|l|l|l|l|l|}
\hline & \multicolumn{3}{|c|}{$\mathbf{9 5 \%} \mathbf{C l}$} & & \\
\hline Independent variable (IV) & b & p-Value & lower & upper & per IV unit \\
\hline Age & 0.052 & $0.002^{*}$ & 1.02 & 1.09 & $5.4 \%$ \\
\hline Pers. AF & 0.017 & $0.001^{* *}$ & 1.01 & 1.03 & $1.7 \%$ \\
\hline Number of cardioversions & 0.201 & $0.001^{\star *}$ & 1.08 & 1.39 & $22.3 \%$ \\
\hline LV-function & -0.045 & $0.001^{\star *}$ & 0.93 & 0.98 & $-4.0 \%$ \\
\hline LA-Diameter & 0.063 & $0.001^{* *}$ & 1.03 & 1.1 & $6.5 \%$ \\
\hline ChadS - -Score & 0.287 & $0.014^{*}$ & 1.06 & 1.68 & $6.5 \%$ \\
\hline
\end{tabular}

Note: ${ }^{*}=$ Significant and ${ }^{* *}=$ Highly significant.

Table 4: Chi-square test (independent variable, IV): type of atrial fibrillation (parox/pers), Vitamin-K antagonists versus nonvitamin $\mathrm{K}$ antagonists, rhythm at TEE, hypertension; dependent variable: spontaneous echo contrast (SEC).

\begin{tabular}{|l|l|l|}
\hline IV & Chi square test iv & Strength of association \\
\hline Type of atrial fibrillation & $\mathrm{X}_{\text {type of AF }}^{2}(1, \mathrm{~N}=540)=47.94, \mathrm{p}<0.001^{* *}$ & $\Phi=0.30(9 \%)$ \\
\hline OAC vs. NOAC & $\mathrm{X}^{2}{ }_{\text {OAK vs NOAK }}(1, \mathrm{~N}=540)=5.32, \mathrm{p}=0.021^{*}$ & $\Phi=0.13(2 \%)$ \\
\hline Rhythm at TEE & $\mathrm{X}_{\text {rhythm at TEE }}^{2}(1, \mathrm{~N}=541)=41.52, \mathrm{p}<0.001^{* *}$ & $\Phi=0.28(8 \%)$ \\
\hline Hypertension & $\mathrm{X}_{\mathrm{HT}}^{2}(1, \mathrm{~N}=538)=10.36, \mathrm{p}<0.001^{* *}$ & $\Phi=0.14(2 \%)$ \\
\hline
\end{tabular}

Note: ${ }^{*}=$ Significant and ${ }^{* *}=$ Highly significant.

Table 5: Distribution of NOACs.

\begin{tabular}{|l|l|l|l|}
\hline NOAC & Total (\%) & no SEC & SEC \\
\hline Dabigatran & $47(18.4 \%)$ & $42(89.4 \%)$ & $5(10.4 \%)$ \\
\hline Apixaban & $56(22 \%)$ & $54(96.4 \%)$ & $2(3.6 \%)$ \\
\hline Rivaroxaban & $152(59.6 \%)$ & $140(92.1 \%)$ & $12(7.1 \%)$ \\
\hline
\end{tabular}

We also found a significant correlation of the CHADS2 and $\mathrm{CHA}_{2} \mathrm{DS}_{\mathrm{c}}-\mathrm{VASC}$ scores with the incidence of SEC $(\mathrm{p}=$ $0.01 / p<0.01$, shown in Table 2, page 12).

\section{Discussion}

The main finding of the study is that patients on NOACs reported significantly less SEC on TEE compared to patients taking VKA in the therapeutic window. All included patients under VKA have been in the target INR range (between 2 and 3). However, it is expected that patients in the lower INR range have a higher risk for SEC than those in the upper target range. In addition, nutritional factors can also lead to strong fluctuations. In terms of safety in thromboembolic and bleeding events, NOACs have been proven to reduce SEC and, thus, the risk of late strokes $[3,4,6,9]$ (Table 4 and Table 5).

Periprocedurally, we did not encounter any stroke or TIA in our patient group, which is consistent with the work of Gedikli, et al. [1] SEC in LA/LAA, therefore, does not seem to be a contraindication for ablation or cardioversion either. Our findings confirm the results of $\mathrm{Di} \mathrm{Bi}-$ ase, et al., that TEE before ablation is not absolutely necessary, especially under sufficient NOAC intake [9-12].

There are reports that during long-term follow-up, patients with preprocedurally detected SEC report significantly more strokes or TIAs [1]. It might be speculated that a change from VKA to NOACs preprocedurally might reduce the frequency of TIA and stroke in the long term. A postprocedural switch could also be discussed in patients on VKA and SEC, although no definite recommendations are possible from ours and other's data.

Impaired left ventricular function, arterial hypertension, AF during TEE, and an enlarged LA were identified as predictors of SEC. These results are consistent with previously published studies and are also included in the CHA ${ }_{2} \mathrm{DS}_{2}$-VASc score [13-15]. An improvement in the left ventricular function caused by optimal medical treatment of heart failure as well as a therapy of arterial hypertension according to the guidelines can reduce the SEC risk mentioned above [16].

Interestingly, the number of previous AF ablations in our cohort was not associated with an increased SEC incidence. Data here are not consistent. The number of ablations and associated ablated areas in the LA may impair LA contractility and, thus, increase the risk for SEC $[17,18]$. Several studies show that left atrial strain is a risk factor for both LA thrombi and SEC $[19,20]$. In addition, the LA-strain is associated with an increased risk of recurrence after ablation [21]. However, we could not confirm this correlation in the present study.

A new finding of the present study is that with the number of external cardioversions performed before ablation, the probability of SEC increases by almost a quarter $(22.3 \%)$. It is also proven that the left atrial function correlates with the risk of recurrence of $A F$ after external cardioversion [22]. For patients with multiple cardioversions (and other additional risk factors), this could mean that echocardiographic thrombus exclusion is recommended even if sufficient oral anticoagulation is consistently administered. The $\mathrm{CHA}_{2} \mathrm{DS}_{2}$-VASc score 
also represents a reliable risk stratification score, and a TEE for thrombus exclusion is recommended for values above 3 points (based on available data).

\section{Limitations}

The available data were collected retrospectively and represent the typical patient population at the time of the investigation. Edoxaban was not yet registered on the European market at the time of data collection.

\section{Conclusion}

The incidence of SEC in patients undergoing TEE prior to AF ablation is significantly lower in patients treated with NOACs than those on VKA. Further studies are necessary to investigate the long-term effect of NOACs on stroke/TIA following AF ablation. In addition to the $\mathrm{CHADS}_{2}$ score parameter, LA diameter, persistent versus paroxysmal $A F$, and the number of previous cardioversions were identified as independent risk factors for SEC. The results support the justifiably increased use of NOACs as first-line oral anticoagulation in non-valvular AF.

\section{Conflicts of Interest}

None of the authors have conflicts of interest to declare.

\section{References}

1. Gedikli Ö, Mohanty S, Trivedi C, Gianni C, Chen Q, et al. (2019) Impact of dense 'smoke' detected on transesophageal echocardiography on stroke risk in patients with atrial fibrillation undergoing catheter ablation. Heart Rhythm 16: 351-357.

2. Chimowitz MI, DeGeorgia MA, Poole RM, Hepner A, Armstrong WM (1993) Left atrial spontaneous echo contrast is highly associated with previous stroke in patients with atrial fibrillation or mitral stenosis. Stroke 24: 1015-1019.

3. Murphy SA, Wiviott SD, Halperin JL, Waldo AL, Ezekowitz, (2017) Dabigatran versus warfarin in patients with atrial fibrillation. Nurs Older People 29: 11.

4. Alexander KP, Brouwer MA, Mulder H, Vinereanu D, Lopes $\mathrm{RD}$, et al. (2019) Outcomes of apixaban versus warfarin in patients with atrial fibrillation and multi-morbidity: Insights from the ARISTOTLE trial. Am Heart J Elsevier Inc 208: 123-131.

5. Uchiyama S, Atarashi $\mathrm{H}$, Inoue $\mathrm{H}$, Kitazono $\mathrm{T}$, Yamashita T, et al. (2019) Primary and secondary prevention of stroke and systemic embolism with rivaroxaban in patients with non-valvular atrial fibrillation: Sub-analysis of the EXPAND Study. Heart Vessels 34: 141-150.

6. Robert P Giugliano, Christian T Ruff, Eugene Braunwald, Sabina A Murphy, Stephen D Wiviott, et al. (2013) Edoxaban versus Warfarin in Patients with Atrial Fibrillation. NEJM 29: 11.

7. Haas S, Camm AJ, Bassand J-P, Angchaisuksiri P, Cools F, et al. (2019) Predictors of NOAC versus VKA use for stroke prevention in patients with newly diagnosed atrial fibrillation: Results from GARFIELD-AF. Am Heart J 11: 35-46.

8. Black W (2000) Spontaneous Echo Contrast : Where There's Smoke There's Fire. Echocardiography 17: 373-382.

9. Cappato R, Ezekowitz, Klein AL, Camm AJ, Ma CS, et al. (2014) Rivaroxaban vs. vitamin $\mathrm{K}$ antagonists for cardioversion in atrial fibrillation. Eur Heart J 35: 3346-3355.

10. Shah D (2017) Diagnostic Electrophysiology \& Ablation Evolution of Force Sensing Technologies Diagnostic Electrophysiology \& Ablation. Arrhythmia Electrophysiol Rev, 75-79.

11. Allan L Klein, Richard A Grimm, Daniel Murray, Carolyn Apperson-Hansen, M Stat, et al. (2001) Use of transesophageal echocardiography to guide cardioversion in patients with atrial fibrillation. N Engl J Med 344: 1411-1420.

12. Biase L Di, Briceno DF, Trivedi C, Mohanty S, Gianni C, et al. (2016) Is transesophageal echocardiogram mandatory in patients undergoing ablation of atrial fibrillation with uninterrupted novel oral anticoagulants? Results from a prospective multicenter registry. Hear Rhythm 13: 11971202.

13. Scherr D, Dalal D, Chilukuri K, Dong J, Spragg D, et al. (2009) Incidence and predictors of left atrial thrombus prior to catheter ablation of atrial fibrillation. J Cardiovasc Electrophysiol 20: 379-384.

14. Frenkel D, D’Amato SA, Al-Kazaz M, Markowitz SM, Liu CF, et al. (2016) Prevalence of Left Atrial Thrombus Detection by Transesophageal Echocardiography: A Comparison of Continuous Non-Vitamin K Antagonist Oral Anticoagulant Versus Warfarin Therapy in Patients Undergoing Catheter Ablation for Atrial Fibrillation. JACC Clin Electrophysiol 2: 295-303.

15. Bertaglia E, Anselmino M, Zorzi A, Russo V, Toso E, et al. (2017) NOACs and atrial fibrillation: Incidence and predictors of left atrial thrombus in the real world. Int $\mathrm{J}$ Cardiol 249: 179-183.

16. Patel VG, Weisse AB, Feuerman M (1996) Reduction of left ventricular spontaneous echo contrast in cardiomyopathy by acute inotropic intervention or aggressive therapy. Clin Cardiol 19: 105-109.

17. Goldman ME, Pearce LA, Hart RG, Zabalgoitia M, Asinger RW, et al. (1999) Pathophysiologic correlates of thromboembolism in nonvalvular atrial fibrillation: I. Reduced flow velocity in the left atrial appendage (The stroke prevention in atrial fibrillation [SPAF-III] study). J Am Soc Echocardiogr 12: 1080-1087.

18. Leung DY, Boyd A, Ng AA, Chi C, Thomas L (2008) Echocardiographic evaluation of left atrial size and function: Current understanding, pathophysiologic correlates, and prognostic implications. Am Heart J 156: 1056-1064.

19. Miyoshi A, Nakamura $Y$, Kazatani $Y$, Ito $H$ (2018) The feasibility of substituting left atrial wall strain for flow velocity of left atrial appendage. Acta Cardiol 73: 125-130.

20. Jankajova M, Kubikova L, Valocik G, Candik P, Mitro P, et al. (2019) Left atrial appendage strain rate is associated with documented thromboembolism in nonvalvular atrial fibrillation. Wien Klin Wochenschr 131: 156-164.

21. Parwani AS, Morris DA, Blaschke F, Huemer M, Pieske B, et al. (2017) Left atrial strain predicts recurrence of atrial arrhythmias after catheter ablation of persistent atrial fibrillation. Open Heart 4: E000572.

22. Rondano E, Dell'Era G, Luca G De, Piccinino C, Bellomo $\mathrm{G}$, et al. (2010) Left atrial asynchrony is a major predictor of 1-year recurrence of atrial fibrillation after electrical cardioversion. J Cardiovasc Med 11: 499-506. 